\title{
Rothia mucilaginosa
}

Generalidades: El género Rothia se encuentra dentro de la familia Micrococcaceae e incluye, al menos, cuatro especies: Rothia dentocariosa, Rothia mucilaginosa, Rothia nasimurium y Rothia amarae, entre otras aún sin denominación. Las dos primeras forman parte de la microbiota de la cavidad orofaríngea y han sido descritas como agentes causales de distintas patologías en humanos, mientras que las dos últimas se han encontrado en ratones y en agua de desagües.

Rothia mucilaginosa, hasta el año 2000 fue denominada Stomatococcus mucilaginosus siendo reclasificada en base a la secuenciación de su rARN 16 s.

En los últimos años se ha descrito como un agente emergente en pacientes inmunocomprometidos y se ha aislado como causante de bacteriemias, endocarditis infecciosa, infecciones del SNC, infecciones urinarias, osteomielitis y peritonitis en pacientes en peritoneo-diálisis, entre otras.

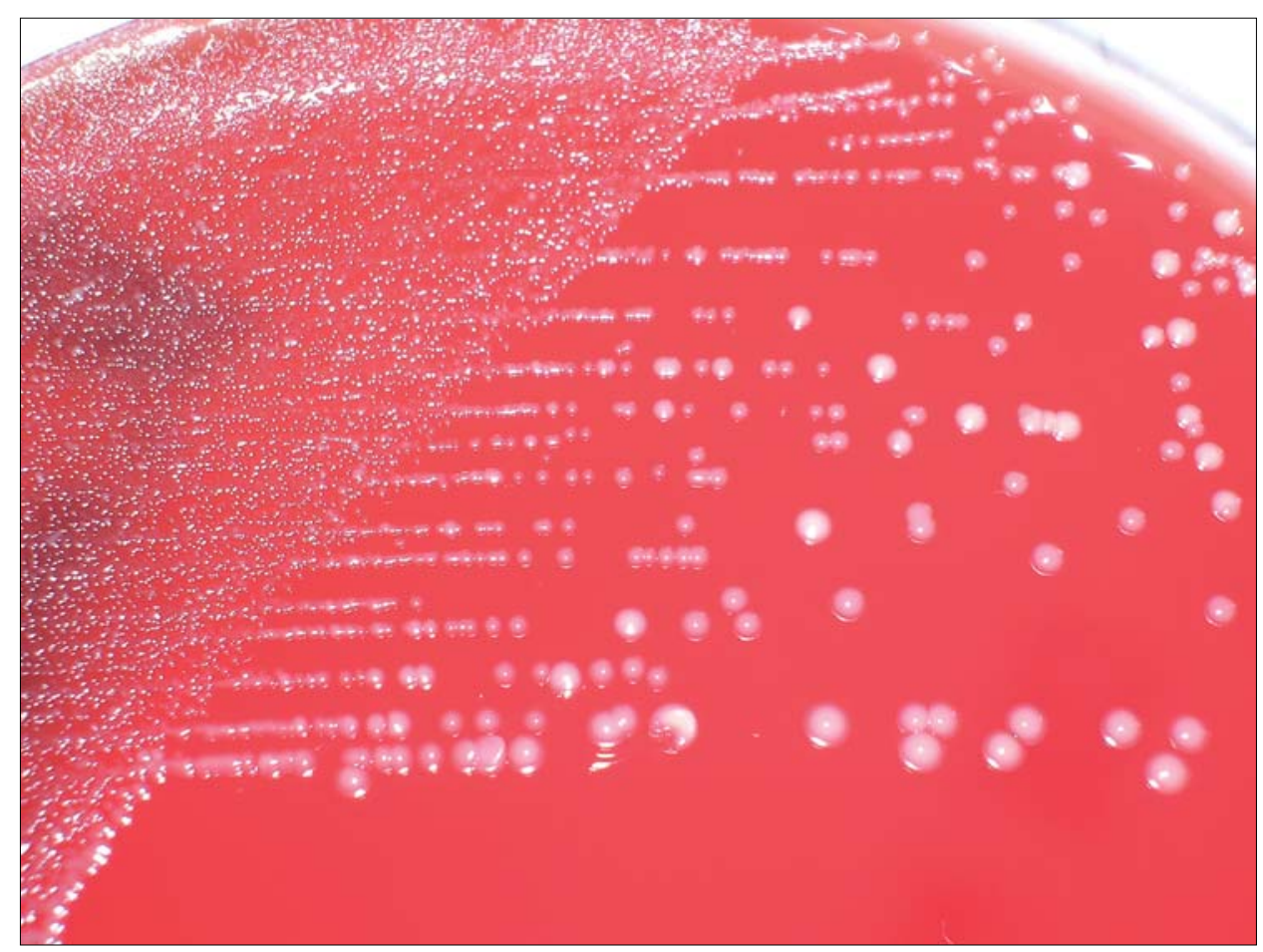

Figura 1. Colonias de Rothia mucilaginosa a las 48 horas de incubación a $35^{\circ} \mathrm{C}$ (medio agar Columbia/sangre de cordero $5 \%$ ).
Características microscópicas: Cocácea grampositiva dispuesta en racimos, tétradas o pares, en algunas ocasiones puede aparecer como un bacilo corto. Cuando es recuperada de medios enriquecidos forma una cápsula voluminosa que puede ser visualizada con tinta china o con tinción de cápsula.

Fisiología: Crece bien en aerobiosis o en ambiente enriquecido en $\mathrm{CO}_{2}$, crece pobremente en anaerobiosis. Se recupera adecuadamente desde frascos de hemocultivos aerobios y en placa de agar sangre se desarrolla en 24 horas a $35^{\circ} \mathrm{C}$. En este medio, las colonias son convexas, mucoides blanquecinas, no hemolíticas (Figura 1). Destacan por su consistencia gomosa y firme adherencia al agar, características que se hacen más notorias al incubar por un tiempo mayor. Esto hace difícil su manipulación y la preparación de una suspensión homogénea para pruebas de identificación y susceptibilidad.
Identificación: La identificación presuntiva se hace a partir de las características de su colonia y la presencia de cápsula. En general, es catalasa variable y no crece en medios con $5 \%$ o más de $\mathrm{NaCl}$. Es oxidasa (-), inmóvil e hidroliza la esculina y la gelatina. La notoria adherencia a la superficie del agar la diferencia del resto de las cocáceas grampositivas catalasa positivas. La diferenciación con $R$. dentocariosa, puede ser difícil, aunque esta última suele presentarse como una tinción de Gram con formas cocobacilares o bacilos difteromorfos.

Susceptibilidad antimicrobiana: No existen puntos de corte establecidos para definir la susceptibilidad de $R$. mucilaginosa; además presenta pobre crecimiento en agar Müller- Hinton o MH suplementado con sangre de cordero. La difícil formación de una suspensión homogénea, dada su consistencia elástica, hace muy difícil el ensayo de susceptibilidad por pruebas de difusión. Estudios por CIM sugieren que habitualmente es sensible a vancomicina y tiene una susceptibilidad variable frente a penicilina, oxacilina, aminoglucósidos y cotrimoxazol. No se ha identificado la presencia de $\beta$ lactamasas; sin embargo, se ha descrito un aumento en la resistencia a quinolonas.

\section{Referencias}

1.- Collins M, Hutson R, Baverud V, Falsen E. Characterization of a Rothia-like organism from a mouse: description of Rothia nasimurium sp. nov. and reclassification of Stomatococcus mucilaginosus as Rothia mucilaginosa comb. nov. Int J Syst Evol Microbiol 2000; 50: 1247-51.

2.- von Graevenitz A. Rothia dentocariosa: taxonomy and differential diagnosis. Clin Microbiol Infect 2004; 10: 399-402.

3.- Marne C. Infecciones por Stomatococcus mucilaginosus: Revisión de la bibliografía. Enferm Infecc Microbiol Clin 2000; 18 : 182-5.

Francisco Silva $\boldsymbol{O}$. Microbiología Servicio de Laboratorio Clínico Hospital Clínico Universidad de Chile 